\title{
Pengujian Blackbox pada Aplikasi Penyimpanan berbasis Android menggunakan Teknik Boundary Value Analysis
}

\author{
Blackbox Testing on Andorid-based Storage Application using the \\ Boundary Value Analysis Technique
}

\author{
Wildan Eri Saputra ${ }^{1}$, Gita Fadila Fitriana ${ }^{* 2}$, Rifki Adhitama ${ }^{3}$ \\ ${ }_{1,2,3}$ Rekayasa Perangkat Lunak, Institut Teknologi Telkom Purwokerto \\ e-mail:17104017@ittelkkom-pwt.ac.id ${ }^{1}$, gita@ittelkom-pwt.ac.id², rifki@ittelkom-pwt.ac.id
}

\begin{abstract}
Abstrak
Mobile app atau yang biasa diketahui dengan aplikasi pada smartphone adalah salah satu bisnis yang tengah ramai di kembangkan oleh banyak orang sekarang untuk memenuhi kebutuhan manusia dalam banyak hal. Mobile app sangat banyak digunakan karena mudah dan hampir setiap orang di indonesia sudah memiliki smartphone. Dari berbagai aplikasi yang dibuat untuk mempermudah pekerjaan manusia, salah satunya adalah aplikasi inventory atau penyimpanan dan pencatatan yang berhubungan dengan aset atau barang yang sangat penting dalam suatu organisasi ataupun perusahaan agar dalam perkembangan usahanya dapat di analisis setiap waktunya. Namun pada setiap pembuatan aplikasi tidak lepas dari testing pada aplikasi untuk mengatasi error yang terjadi saat aplikasi yang digunakan. Untuk mengatasi dan mencari bug dan error yang terdapat pada aplikasi maka dibuatlah pengujian terhadap aplikasi penyimpanan menggunakan metode black box testing dengan teknik boundary value analysis (BVA). BVA adalah salah satu pengujian untuk mencari kesalahan dalam aplikasi dengan sudut pandang pengguna dengan menguji nilai batas pada batas atas dan juga batas bawah dengan tahapan mengidentifikasi masalah, pemilihan data uji, data uji, pengujian menggunakan boundary value analysis dan juga dokumentasi. Hasil penelitian menggunakan boundary value analisis secara keseluruhan mempunyai prosentase keberhasilan aplikasi setelah dilakukan pengujian adalah 5:1 dengan rate keberhasilan mencapai $83,33 \%$.
\end{abstract}

Kata Kunci: Boundary Value Analysis, Mobile app, Pengujian Blackbox, Smartphone

\begin{abstract}
Mobile app or commonly known as an application on a smartphone is one of the businesses that is currently being developed by many people to meet human needs in many ways. Mobile apps are very widely used because they are easy and almost everyone in Indonesia already has a smartphone. Of the various applications made to facilitate human work, one of which is the application of inventory or storage and recording related to assets or goods that are very important in an organization or company so that in the development of their business they can be analyzed at any time. However, every application creation cannot be separated from testing the application to overcome errors that occur when the application is used. To overcome and look for bugs and errors contained in the application, a test was made on the storage application using the black box testing method with the boundary value analysis (BVA) technique. BVA is one of the tests to find errors in applications from the user's point of view by testing the limit values at the upper and lower limits with the stages of identifying problems, selecting test data, test data, testing using boundary value analysis and also documentation. The results of the study using boundary value analysis as a whole have a success percentage of the application after testing is 5:1 with a success rate of $83.33 \%$.
\end{abstract}

Keywords: Boundary Value Analysis, Mobile app, Blackbox testing, Smartphone

\section{Pendahuluan}

Perkembangan teknologi yang sangat pesat dalam beberapa tahun terakhir memunculkan banyak peluang usaha dibidang digital, khususnya pada aplikasi berbasis mobile app yang menimbulkan beberapa dampak dalam aspek masyarakat, bisnis, pendidikan, pemerintahan, hiburan, bahkan dalam aspek kehidupan pribadi. Dengan perkembangan mobile app saat ini, aplikasi mobile memberikan keuntungan dalam aksesnya karena aplikasi mobile tidak memerlukan instalasi yang sulit dan tidak membutuhkan biaya dan waktu yang lama, semua perangkat yang terhubung di internet dapat mengakses berbagai aplikasi yang 
tersedia di app store untuk mendapatkan berbagai informasi untuk membantu dalam kehidupan sehari hari. Menururt prediksi www.databoks.katadata.co.id kenaikan jumlah penggunaan smartphone dari rentang waktu 2015 sampai 2020 mencapai 70,1\% dengan kata lain sudah lebih dari setengah rakyat Indonesia bisa menggunakan smartphone dan akan terus naik setiap tahunnya.

Aplikasi yang baik harus dilakukan pengujian untuk kepentingan pemakai, sehingga diperlukan pelaporan dan evaluasi ulang terhadap pengujian [1]. Pengujian perangkat lunak bertujuan untuk menemukan sebuah kesalahan yang bisa menyebabkan perangkat lunak yang telah di bangun akan terjadi error dalam fungsionalitasnya. Selain tujuan diatas, pengujian perangkat lunak juga bertujuan untuk memperoleh produk yang berkualitas dan memberikan produktivitas tinggi. Produk yang berkualitas tinggi itu bergantung kepada kepuasan pelanggan atau pengguna [2].

Penelitian sebelumnya mengenai Penerapan teknik boundary value analysis untuk proses pengujian aplikasi kantor digital pada salah satu fungsionalitas yaitu surat masuk. Dengan pada beberap tahapan yang dicoba pada fungsionalitas form surat masuk, form ini terdiri dari 9 field entri data. Setelah dilakukan pengujian menunjukan aplikasi mampu menangani data, data tidak normal maupun data normal dengan presentasi keberhasilan 91,67\% [3].

Aplikasi penggajian pegawai dengan metode equivalnce patition yang dimana teknik ini adalah salah satu dari metode blackbox. Perbedaan terlihat jelas dari alur penetiannya dan pada penelitian ini febrian menetapkan kondisi berhasil apabila mempu memunculkan kesalahan dari program yang sedang diuji. Perbedaan teknik ini bisa memunculkan manfaat dalam penelitian penelitan selanjutnya dalam segi metodologi untuk pengujian yang lebih baik kedepannya. Penelitian yang dilakukan Febrian sangat membantu dalam penjelasan mengenai blackbox testing dan bisa menjadi salah satu acuan dalam penelitian menggunakan metode black box.Pengujian aplikasi penggajian pegawai dengan menggunakan metode black box digunakan untuk menguji tingkat kesalahan sistem agar sistem berjalan dengan baik sehingga memudahkan pengguna dan hasil dari pengujian ini sesuai dengan yang diharapkan karena dari 2 form yaitu form penggajian dan data gaji dengan 4 kali pengujian mendapatkan hasil dengan success [4].

Penelitian dengan metode black box testing yang difokuskan pada metode Boundary Value Analysis dimana kesalahan kerap kali timbul pada batas kesetaraan kelas. Perihal ini terjadi karena batasan sering kali tidak didefinisikan secara jelas. Pengujian BVA dilakukan karena belum adanya pengujian BVA yang dilakukan pada form tambah pelanggan yang ada pada aplikasi penyimpanan dan bagaimana melakukan pengujian menggunakan metode BVA. Pengujian ini dilakukan pada form tambah pelanggan dikarenakan memiliki komponen form yang cukup lengkap dan merupakan form fungsional utama untuk menyimpan data pelanggan pada aplikasi penyimpanan. Metode ini bisa diterapkan bila sekumpulan informasi pada kelas kesetaraan sudah disusun dan mempunyai batasan yang bisa di identifikasi. Boundary Value Analysis memeriksa batasan kelas kesetaraan. Pada tiap batas, nilai batasan yang tepat serta kedua nilai yang berdekatan diuji terhadap suatu perangkat lunak [5]

Pengujian aplikasi penjualan berbasis web sangat membantu dalam pengarahan alur pengujian sehingga untuk menjadi salah satu acuan yang bagus dalam pengujian blackbox dengan teknik boundary value analysis. Hasil dari pengujian fungsionalitas form tambah barang adalah sukses $100 \%$ [6]. Aplikasi Online marketplace memiliki model bisnis concentrator dimana pemilik online shop adalah hanya sebagai fasilitator yang menampung berbagai informasi tentang produk dan jasa dari berbagai penjual sehingga pembeli bisa membandingkan harga. Aplikasi ini dilakukan pengujian blackbox, pengujian dilakukan dengan BVA dan hasilnya $100 \%$ berhasil [7].

Pada penelitian kali ini dilakukan mengguankan Boundary Value Analysis untuk menguji aplikasi prediksi kelulusan SNMPTN, pada penelitian ini belum adanya alur penelitian terhadap boundary value analysis, hal ini tidak sejalan dengan penelitian penelitian lainnya dengan teknik serupa. Pada penelitian ini belum adanya kejelasan terhadap aturan entri pada setiap field yang diuji sehingga membuat pembaca bingung. Penelitian ini berfokus padaform tambah kelas yang memiliki 3 field yaitu jurusan, nama kelas, dan tahun ajaran. Hasil dari penelitian belum dideskripsikan secara jelas sehingga membuat pembaca harus melihat manual hasil dari pengujian melalui table. Hasil pengujian memperlihatkan bahwa aplikasi masih mempunyai beberapa kekurangan dan kecacatan yaitu belum lengkapnya proses pada validasi data dan memerlukan penyempurnaan dengan menambah fungsi validasi [8].

Penelitian ini Boundary Value Analysis dimana tes dirancang untuk mencakup perwakilan dari nilai batas dalam kisaran melalui beberapa tahapan uji yang telah ditentukan untuk masing masing field dan membuat suatu kasus untuk digunakan dalam pengujian. Hasil penelitian ini mempunyai entri data yang terlalu sedikit untuk melakukan pengujian dan juga dalam pengujiannya belum mempunyai alur penelitian yang jelas sehingga membuat bingung pembaca. Hasil pengujian memperlihatkan bahwa tingkat 
keberhasilan aplikasi hanya berjalan $80 \%$. Aplikasi ini perlu dimaintenance untuk meningkatkan kualitas aplikasi dalam menghitung nilai dari 0 - 100 sebagaimana fungsinya [9]. Pengujian sistem bertujuan untuk mengevaluasi kemampuan aplikasi dan menentukan apakah program yang dikembangkan sudah sesuai dengan hasil yang diharapkan. Hal ini juga bertujuan untuk memastikan bahwa aplikasi memiliki kualitas terbaik dan terpelihara [10].

Aplikasi inventory ini memiliki banyak fitur yang memiliki fungsi berbeda beda. Namun pada pengujuan saat ini dipilih sampel pada Form tambah pelanggan karena memiliki komponen forrn yang cukup lengkap dan dapat mewakili form lainnya Pada penelitian ini, hendak dilakukan suatu pengujian menggunakan metode black box testing yang berfokus pada metode Boundary Value Analysis.

\section{Metode Penelitian}

Tahapan sebagai pedoman dalam melakukan penelitian atau pengujian agar sesuai dengan tujuan. Beberapa tahapannya adalah identifikasi masalah, Pemilihan data uji, Data Uji, Pengujian Boundary Value Analysis, dan Dokumentasi. Alur penelitian dapat dilihat pada Gambar 1.

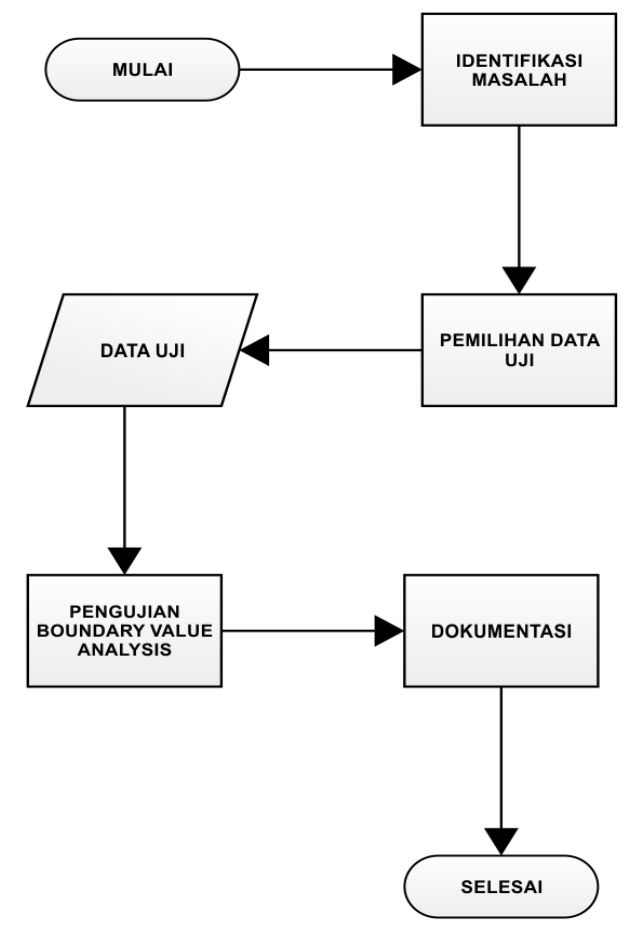

Gambar 1. Tahapan penelitian

\section{Identifikasi Masalah}

Tahapan awal pada pengujian ini adalah menentukan metode dan Teknik apa yang akan digunakan dan pada pengujian kali ini penguji akan menggunakan metode pengujian Black Box dengan Teknik Boundary Value Analysis. Data yang akan diuji adalah sebuah form tambah pelanggan dengan penerapan pengujian memasukkan Batasan atas dan Batasan bawah pada form tambah pelanggan.

\section{Pemilihan Data Uji}

Pada tahap ini saya melakukan pemilihan atau screening di awal terhadap data uji saya yang dimana memiliki spesiifkasinya:

1. Nama dengan tipe data String yang dimana terdiri dari huruf dan tidak boleh ada nomor atau bilangan, karakter atau integer pada field nama dan juga Perhatikan Uppercase dan Lowercase 
nya huruf yang di input karena data akan tersimpan sesuai dengan besar kecil huruf yang di simpan.

2. Username dengan tipe data string yang dimana terdiri dari huruf dan dipebolehkan menggunakan nomor atau bilangan dan karakter field Username tetapi karakter terdepan wajib menggunakan huruf dan juga Perhatikan Uppercase dan Lowercase nya huruf yang di input karena data akan tersimpan sesuai dengan besar kecil huruf yang di simpan.

3. Password dengan tipe data string yang dimana terdiri dari huruf dan dipebolehkan menggunakan nomor atau bilangan dan karakter field Pasword karakter karena pada field ini semakin banyak karakter semakin aman akun atau sandi kita di retas oleh hacker dan juga Perhatikan Uppercase dan Lowercase nya huruf yang di input karena data akan tersimpan sesuai dengan besar kecil huruf yang di simpan.

4. Alamat dengan tipe data string yang dimana terdiri dari huruf dan dipebolehkan menggunakan nomor atau bilangan dan karakter field Alamat karakter dan juga Perhatikan Uppercase dan Lowercase nya huruf yang di input karena data akan tersimpan sesuai dengan besar kecil huruf yang di simpan dan juga pada field alamat diharuskan menekan tombol tambah koordinat yang sudah tersedia sehingga akan terdeteksi secara otomatis melalui aplikasi google map dimana letak dari alamat.

5. Nomor hp pelanggan terdiri dari Nomor atau bilangan dan tidak boleh ada huruf atau karakter selain nomor.

\section{Data Uji}

Data uji yang akan saya gunakan yaitu tambah pelanggan dimana field yang akan diuji merupakan form fungsional utama untuk menyimpan data pelanggan pada aplikasi penyimpanan, pada form tambah pelanggan ini memiliki field sebagai berikut:

Tabel 1. Field data Uji

\begin{tabular}{c|c|c}
\hline Form & Field & Elemen \\
\hline Input Pelanggan & Nama & String \\
& String & String \\
& String & String \\
\hline
\end{tabular}

Pada tabel 1, menunjukan field data uji form tambah pelanggan yang terdiri atas field nama, username, password, alamat, dan nomor HP. Field tersebut akan dilakukan pengujian. Pada masing-masing field memiliki elemen string. Field-field tersebut dilakukan pengujian blackbox dengan metode boundary value analysis.

\section{Pengujian Boundary Value Analysis}

Pengujian Boundary Value Analysis ini dilakukan pada Form Tambah Pelanggan dengan rancangan pengujian sebagai berikut:

Tabel 2. Skenario data uji

\begin{tabular}{|c|c|c|c|}
\hline ID & Field yang diuji & Skenario Pengujian & Hasil diharapkan \\
\hline 1. & Field Nama & $\begin{array}{l}\text { Field terdiri dari huruf dan tidak boleh ada nomor atau } \\
\text { bilangan, karakter atau integer pada field nama. }\end{array}$ & $\begin{array}{l}\text { - Tidak ada pesan kesalahan. } \\
\text { - Tidak tersimpan pada database Ketika } \\
\text { terdapat karakter selain huruf }\end{array}$ \\
\hline 2. & Field Username & $\begin{array}{l}\text { Field terdiri dari huruf dan dipebolehkan menggunakan } \\
\text { nomor atau bilangan dan karakter field Username tetapi } \\
\text { karakter terdepan wajib menggunakan huruf dan juga } \\
\text { Perhatikan Uppercase dan Lowercase nya huruf yang di } \\
\text { input karena data akan tersimpan sesuai dengan besar } \\
\text { kecil huruf yang di simpan. }\end{array}$ & $\begin{array}{l}\text { - Tidak ada pesan kesalahan. } \\
\text { - Data yang tersimpan sesuai dengan } \\
\text { karakter yang di masukan pada field }\end{array}$ \\
\hline 3 & Field Password & $\begin{array}{l}\text { Terdiri dari huruf dan dipebolehkan menggunakan } \\
\text { nomor atau bilangan dan karakter field Pasword karakter } \\
\text { karena pada field Password. }\end{array}$ & $\begin{array}{l}\text { - } \quad \text { Tidak ada pesan kesalahan. } \\
\text { - } \quad \text { Data yang tersimpan sesuai dengan } \\
\text { karakter yang di masukkan pada field. }\end{array}$ \\
\hline
\end{tabular}




\begin{tabular}{l|l|l|l}
4 & Field Alamat & $\begin{array}{l}\text { Diharuskan menekan tombol tambah koordinat yang } \\
\text { sudah tersedia sehingga akan terdeteksi secara otomatis } \\
\text { melalui aplikasi google map dimana letak dari alamat } \\
\text { namun bisa ditambahkan dengan huruf atau karakter } \\
\text { apabila belum lengkap pada field ini. }\end{array}$ & $\begin{array}{l}\text { Tidak ada pesan kesalahan. } \\
\text { Data yang tersimpan sesuai dengan } \\
\text { karakter yang di masukkan pada field } \\
\text { dan setelah ditambahkan Ketika } \\
\text { alamat telah ditambahkan secara } \\
\text { manual. }\end{array}$ \\
& Field Nomor HP & $\begin{array}{l}\text { Field ini harus terdiri dari Nomor atau bilangan dan tidak } \\
\text { boleh ada huruf atau karakter selain nomor. }\end{array}$ & $\begin{array}{l}\text { Tidak ada pesan kesalahan. } \\
\text { Tidak tersimpan pada database Ketika } \\
\text { terdapat karakter selain nomor. }\end{array}$ \\
\hline
\end{tabular}

Pada tabel 2, field-field dirancang skenario pengujian dengan menentukan hasil yang diharapkan sebagai tolak ukur keberhasilan.

\section{Dokumentasi}

Tahap Keenam adalah menghitung hasil pengujian berdasarkan persentase yang dihasilkan saat pengujian dilakukan kemudian melakukan dokumentasi untuk pelaporan pengujian.

\section{Hasil dan Pembahasan}

Berdasarkan Penjabaran sebelumnya, dicoba diterapkan Teknik Boundary Value Analysis untuk menguji aplikasi penyimpanan. Aplikasi ini memuat beberapa fungsi dan modul, namun pada artikel ini sebagai akan membahas hasil pengujian pada salah satu fungsionalitas yaitu "Tambah Pelanggan". Fungsi "Tambah Pelanggan" terdiri atas satu panel entri data seperti pada Gambar 4.1 pada form terdapat 5 field entri data yaitu Nama, username, Password, Alamat, dan Nomor HP.

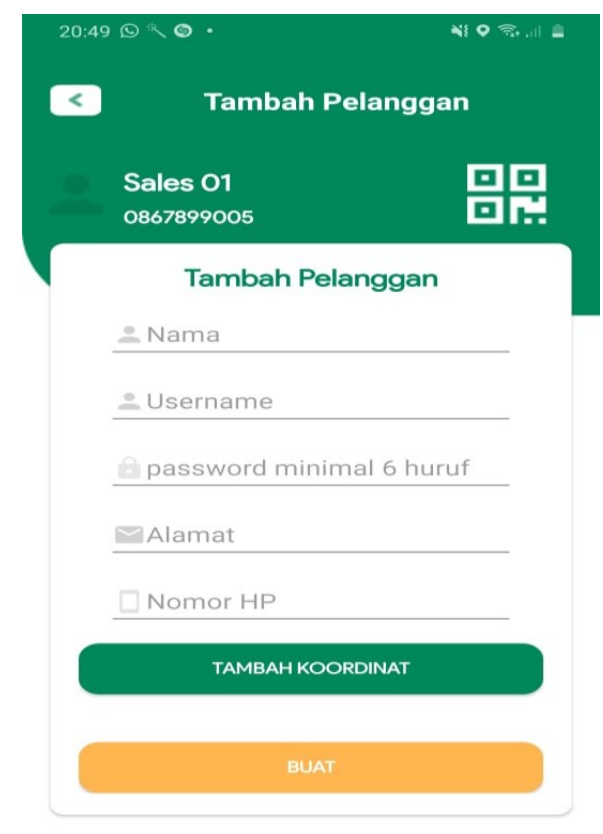

Gambar 2. Tambah pelanggan

Dari Form diatas masing-masing field mempunyai elemen-elemen input tersendiri yang dapat dilihat melalui Tabel 1. Berdasarkan form di atas, kemudian akan dilakukan pengujian dengan menyiapkan beberapa data uji. Dari bentuk form di atas, contoh pengujian akan dilakukan pada semua field yaitu Nama, Username, Password, Alamat, dan Nomor HP dengan scenario pengujian dan hasil ujinya.

\section{Analisa Hasil dan Pembahasan}

JINITA Vol. 3, No. 2, Desember 2021 
Form diatas memiliki beberapa field yang harus diisi agar penambahan data pelanggan bisa dilakukan, yaitu dengan mengisi Nama, Username, Password, Alamat, dan Nomor HP. Tombol BUAT berfungsi agar data yang sudah dimasukkan dapat tersimpan di database. Untuk melakukan pengujian setiap field pada form telah di siapkan beberapa skenario pengujian yang bertujuan untuk menangani berbagai macam input yang diberikan oleh pengguna. Berdasarkan pengujian Boundary Value Analysis, didapatkan test case pengujian.

\section{Pengujian field "Nama"}

Aturan entri data A.1 : harus terdiri dari huruf dan tidak boleh ada nomor atau bilangan, karakter atau integer pada field nama dan juga Perhatikan Uppercase dan Lowercase nya huruf yang di input karena data akan tersimpan sesuai dengan besar kecil huruf yang di simpan.

Tabel 2. Hasil uji aturan A.1

\begin{tabular}{|c|c|c|c|c|}
\hline No & Sample Data & Expected Result & Result & Conclusion \\
\hline 1. & Budi Priyanto & $\mathrm{T}$ & $\mathrm{T}$ & Success \\
\hline 2. & Dicky Rizkyawan & $\mathrm{T}$ & $\mathrm{T}$ & Success \\
\hline 3. & Syarif & $\mathrm{T}$ & $\mathrm{T}$ & Success \\
\hline 4. & Keysya & $\mathrm{T}$ & $\mathrm{T}$ & Success \\
\hline 5. & anugrah ananda adi guna & $\mathrm{T}$ & $\mathrm{T}$ & Success \\
\hline 6. & Raya Fama & $\mathrm{T}$ & $\mathrm{T}$ & Success \\
\hline 7. & Jundi Abdul Ghoffar Al Mudhofar & $\mathrm{T}$ & $\mathrm{T}$ & Success \\
\hline 8. & fahrul badawi & $\mathrm{T}$ & $\mathrm{T}$ & Success \\
\hline 9. & steven & $\mathrm{T}$ & $\mathrm{T}$ & Success \\
\hline 10. & aji & $\mathrm{T}$ & $\mathrm{T}$ & Success \\
\hline 11. & Ahmad Jauhari & $\mathrm{T}$ & $\mathrm{T}$ & Success \\
\hline 12. & Aditya Wira Praharsa & $\mathrm{T}$ & $\mathrm{T}$ & Success \\
\hline 13. & Muhammad Yudha Galih & $\mathrm{T}$ & $\mathrm{T}$ & Success \\
\hline 14. & sabrizen & $\mathrm{T}$ & $\mathrm{T}$ & Success \\
\hline 15. & Doni Rizqi S & $\mathrm{T}$ & $\mathrm{T}$ & Success \\
\hline 16. & yogi muhammad ihsan & $\mathrm{T}$ & $\mathrm{T}$ & Success \\
\hline 17. & Muhammad Aditya Prayogi & $\mathrm{T}$ & $\mathrm{T}$ & Success \\
\hline 18. & ahmadbarber & $\mathrm{T}$ & $\mathrm{T}$ & Success \\
\hline 19. & Apriyansyah dwi sp & $\mathrm{T}$ & $\mathrm{T}$ & Success \\
\hline 20. & Komang Agustia & $\mathrm{T}$ & $\mathrm{T}$ & Success \\
\hline 21. & Adul Steve & $\mathrm{T}$ & $\mathrm{T}$ & Success \\
\hline 22. & Arman Darmawan & $\mathrm{T}$ & $\mathrm{T}$ & Success \\
\hline 23. & martin & $\mathrm{T}$ & $\mathrm{T}$ & Success \\
\hline 24. & Dimas Widianto & $\mathrm{T}$ & $\mathrm{T}$ & Success \\
\hline 25. & Gorja Dwipra & $\mathrm{T}$ & $\mathrm{T}$ & Success \\
\hline 26. & Fikri Ramadhani & $\mathrm{T}$ & $\mathrm{T}$ & Success \\
\hline 27. & Muhammad budi Setiawan & $\mathrm{T}$ & $\mathrm{T}$ & Success \\
\hline 28. & Fikri Akbar & $\mathrm{T}$ & $\mathrm{T}$ & Success \\
\hline 29. & BILLY RAHAGY S & $\mathrm{T}$ & $\mathrm{T}$ & Success \\
\hline 30. & Triehani & $\mathrm{T}$ & $\mathrm{T}$ & Success \\
\hline
\end{tabular}

Data Tabel 2 menunjukkan dari 30 orang responden, terdapat 26 success dan 4 failed. Data berstatus failed atau gagal karena kondisi keberhasilan pengujian form tambah pelanggan diukur dari masuknya data yang telah diisikan pada field kedalam database dari aplikasi penyimpanan sehingga apabila ada satu field dari kelima field yang tidak memenuhi kondisi atau melebihi aturan batasan dari field, maka 1 form akan dianggap gagal karena data tidak masuk kedalam database aplikasi penyimpanan.

\section{Pengujian field "Username"}

Aturan entri data A.2 : harus terdiri dari huruf dan dipebolehkan menggunakan nomor atau bilangan dan karakter field Username tetapi karakter terdepan wajib menggunakan huruf dan juga Perhatikan Uppercase dan Lowercase nya huruf yang di input karena data akan tersimpan sesuai dengan besar kecil huruf yang di simpan.

Tabel 3. Hasil uji aturan A.2 


\begin{tabular}{|c|c|c|c|c|}
\hline No & Sample Data & Expected Result & Result & Conclusion \\
\hline 1. & Budi Priyanto & $\mathrm{T}$ & $\mathrm{T}$ & Success \\
\hline 2. & Drizone & $\mathrm{T}$ & $\mathrm{T}$ & Success \\
\hline 3. & Muhsya28 & $\mathrm{T}$ & $\mathrm{T}$ & Success \\
\hline 4. & Keysya.mmr & $\mathrm{T}$ & $\mathrm{T}$ & Success \\
\hline 5. & adi guna & $\mathrm{T}$ & $\mathrm{T}$ & Success \\
\hline 6. & rayafama06 & $\mathrm{T}$ & $\mathrm{T}$ & Success \\
\hline 7. & Jundi_ & $\mathrm{T}$ & $\mathrm{T}$ & Success \\
\hline 8. & Fahrul1를 & $\mathrm{T}$ & $\mathrm{T}$ & Success \\
\hline 9. & stevenogiwara & $\mathrm{T}$ & $\mathrm{T}$ & Success \\
\hline 10. & trisetioaji & $\mathrm{T}$ & $\mathrm{T}$ & Success \\
\hline 11. & @Jawwller & $\mathrm{F}$ & $\mathrm{T}$ & Failed \\
\hline 12. & Adit & $\mathrm{T}$ & $\mathrm{T}$ & Success \\
\hline 13. & Yudha galih & $\mathrm{T}$ & $\mathrm{T}$ & Success \\
\hline 14. & sabrizen & $\mathrm{T}$ & $\mathrm{T}$ & Success \\
\hline 15. & donirizqi & $\mathrm{T}$ & $\mathrm{T}$ & Success \\
\hline 16. & yogi & $\mathrm{T}$ & $\mathrm{T}$ & Success \\
\hline 17. & Aditya & $\mathrm{T}$ & $\mathrm{T}$ & Success \\
\hline 18. & Ahmadbarber & $\mathrm{T}$ & $\mathrm{T}$ & Success \\
\hline 19. & apriyansyahdsp & $\mathrm{T}$ & $\mathrm{T}$ & Success \\
\hline 20. & Gustia & $\mathrm{T}$ & $\mathrm{T}$ & Success \\
\hline 21. & admin & $\mathrm{T}$ & $\mathrm{T}$ & Success \\
\hline 22. & Arman9darmawan & $\mathrm{T}$ & $\mathrm{T}$ & Success \\
\hline 23. & Martin & $\mathrm{T}$ & $\mathrm{T}$ & Success \\
\hline 24. & Dimas & $\mathrm{T}$ & $\mathrm{T}$ & Success \\
\hline 25. & Dwipra & $\mathrm{T}$ & $\mathrm{T}$ & Success \\
\hline 26. & FikriRamadhani & $\mathrm{T}$ & $\mathrm{T}$ & Success \\
\hline 27. & Muhammad budi setiawan & $\mathrm{T}$ & $\mathrm{T}$ & Success \\
\hline 28. & user & $\mathrm{T}$ & $\mathrm{T}$ & Success \\
\hline 29. & BILLY & $\mathrm{T}$ & $\mathrm{T}$ & Success \\
\hline 30. & Trie & $\mathrm{T}$ & $\mathrm{T}$ & Success \\
\hline
\end{tabular}

\section{Pengujian field "Password"}

Aturan entri data A.3 : harus terdiri dari huruf dan dipebolehkan menggunakan nomor atau bilangan dan karakter field Pasword karakter karena pada field ini semakin banyak karakter semakin aman akun atau sandi kita di retas oleh hacker dan juga Perhatikan Uppercase dan Lowercase nya huruf yang di input karena data akan tersimpan sesuai dengan besar kecil huruf yang di simpan.

Tabel 4. Hasil uji aturan A.3

\begin{tabular}{c|c|c|c|c}
\hline No & Sample Data & Expected Result & Result & Conclusion \\
\hline 1. & Passwordnya budi & $\mathrm{T}$ & $\mathrm{T}$ & Success \\
2. & Dri012 & $\mathrm{T}$ & $\mathrm{T}$ & Success \\
3. & Soady1991 & $\mathrm{T}$ & $\mathrm{T}$ & Success \\
\hline
\end{tabular}

JINITA Vol. 3, No. 2, Desember 2021 


\begin{tabular}{|c|c|c|c|c|}
\hline 4. & 123456 & $\mathrm{~T}$ & $\mathrm{~T}$ & Success \\
\hline 5. & Papaberuang150102 & $\mathrm{T}$ & $\mathrm{T}$ & Success \\
\hline 6. & RayaTahun20 & $\mathrm{T}$ & $\mathrm{T}$ & Success \\
\hline 7. & jundiabdd & $\mathrm{T}$ & $\mathrm{T}$ & Success \\
\hline 8. & fahrul123 & $\mathrm{T}$ & $\mathrm{T}$ & Success \\
\hline 9. & St202003 & $\mathrm{T}$ & $\mathrm{T}$ & Success \\
\hline 10. & Ajip321 & $\mathrm{T}$ & $\mathrm{T}$ & Success \\
\hline 11. & 123456 & $\mathrm{~T}$ & $\mathrm{~T}$ & Success \\
\hline 12. & 1234567 & $\mathrm{~T}$ & $\mathrm{~T}$ & Success \\
\hline 13. & 150503Aceh & $\mathrm{T}$ & $\mathrm{T}$ & Success \\
\hline 14. & sabrizen & $\mathrm{T}$ & $\mathrm{T}$ & Success \\
\hline 15. & Siputmati12 & $\mathrm{T}$ & $\mathrm{T}$ & Success \\
\hline 16. & Sukabumi 123 & $\mathrm{~T}$ & $\mathrm{~T}$ & Success \\
\hline 17. & Aditya & $\mathrm{T}$ & $\mathrm{T}$ & Success \\
\hline 18. & Nashir1234 & $\mathrm{T}$ & $\mathrm{T}$ & Success \\
\hline 19. & 23446 & $\mathrm{~T}$ & $\mathrm{~T}$ & Success \\
\hline 20. & qwerty & $\mathrm{T}$ & $\mathrm{T}$ & Success \\
\hline 21. & Cobapas & $\mathrm{T}$ & $\mathrm{T}$ & Success \\
\hline 22. & 654321 & $\mathrm{~T}$ & $\mathrm{~T}$ & Success \\
\hline 23. & martin & $\mathrm{T}$ & $\mathrm{T}$ & Success \\
\hline 24. & Gore123 & $\mathrm{T}$ & $\mathrm{T}$ & Success \\
\hline 25. & qwerty & $\mathrm{T}$ & $\mathrm{T}$ & Success \\
\hline 26. & 12345678 & $\mathrm{~T}$ & $\mathrm{~T}$ & Success \\
\hline 27. & userpass & $\mathrm{T}$ & $\mathrm{T}$ & Success \\
\hline 28. & 123456 & $\mathrm{~T}$ & $\mathrm{~T}$ & Success \\
\hline 29. & 654321 & $\mathrm{~T}$ & $\mathrm{~T}$ & Success \\
\hline 30. & 123456 & $\mathrm{~T}$ & $\mathrm{~T}$ & Success \\
\hline
\end{tabular}

\section{Pengujian field "Alamat"}

Aturan entri data A.4 : harus terdiri dari huruf dan dipebolehkan menggunakan nomor atau bilangan dan karakter field Alamat karakter dan juga Perhatikan Uppercase dan Lowercase nya huruf yang di input karena data akan tersimpan sesuai dengan besar kecil huruf yang di simpan dan juga pada field alamat diharuskan menekan tombol tambah koordinat yang sudah tersedia sehingga akan terdeteksi secara otomatis melalui aplikasi google map dimana letak dari alamat.

Tabel 5. Hasil uji aturan A.4

\begin{tabular}{|c|c|c|c|c|}
\hline No & Sample Data & $\begin{array}{c}\text { Expected } \\
\text { Result }\end{array}$ & Result & Conclusion \\
\hline 1. & $\begin{array}{c}\text { J1 Anggrek Situbondo, Situbondo, Jawa Timur, Indonesia } \\
\text { Kab: Grobogan Kect:Karangrayung Kel: Mangin Dsn:Pulo Rt:002 }\end{array}$ & $\mathrm{T}$ & $\mathrm{T}$ & Success \\
\hline 2. & $\begin{array}{c}\text { Rw:001,Pulo,Mangin,Kec.Karangrayung,Kabupaten Grobogan,Jawa Tengah } \\
\text { 58163,Indonesia }\end{array}$ & $\mathrm{T}$ & $\mathrm{T}$ & Success \\
\hline 3. & $\begin{array}{c}\text { Jl. Rajawali No 74, Ngebel, Tamantirto, Kec. Kasihan, Bantul, Daerah } \\
\text { Istimewa Yogyakarta 55184, Indonesia }\end{array}$ & $\mathrm{T}$ & $\mathrm{T}$ & Success \\
\hline 4. & $\begin{array}{c}\text { Unnamed Road,Rejosari,Pengkoljagong,Jati,Kabupaten Blora,Jawa Tengah } \\
\text { 58384,Indonesia }\end{array}$ & $\mathrm{T}$ & $\mathrm{T}$ & Success \\
\hline 5. & $\begin{array}{l}\text { JL.Datuk Tunggul,Sidomulyo Bar., Kec.Tampan,Kota Pekanbaru,Riau } \\
\text { 28294,Indonesia }\end{array}$ & $\mathrm{T}$ & $\mathrm{T}$ & Success \\
\hline 6. & $\begin{array}{c}\text { JL.Pesantren Blok Mujem No.43,Rt.001/Rw.004 Kreo Selatan,Kec } \\
\text { Larangan,Kota tangerang,Banten 15156,Indonesia }\end{array}$ & $\mathrm{T}$ & $\mathrm{T}$ & Success \\
\hline 7. & $\begin{array}{c}\text { JL.Ketawang Teges Lor,Ketangrejo,Kec.Grabag.Kabupaten Purworejo,Jawa } \\
\text { Tengah 54265,Indonesia }\end{array}$ & $\mathrm{T}$ & $\mathrm{T}$ & Success \\
\hline 8. & FahrulBadawi@gmail.com & $\mathrm{F}$ & $\mathrm{T}$ & Failed \\
\hline 9. & $\begin{array}{c}\text { JL. Jend. Gatot Subroto, Mertangga, Jetis, Nusawungu, Kabupaten Cilacap, } \\
\text { Jawa Tengah 53283, Indonesia }\end{array}$ & $\mathrm{T}$ & $\mathrm{T}$ & Success \\
\hline 10. & $\begin{array}{l}\text { JL. Lintas Sumatra No. 172, Bukit Tigo, Singkut, Kabupaten Sarolangun, } \\
\text { Jambi 37482, Indonesia }\end{array}$ & $\mathrm{T}$ & $\mathrm{T}$ & Success \\
\hline 11. & $\begin{array}{l}\text { JL.Poltangan Raya No.44A, Rt.2/Rw.11,Pejaten Tim., Kec. Ps.Minggu,Kota } \\
\text { Jakarta Selatan, Daerah khusus Ibukota Jakarta 12530,Indonesia }\end{array}$ & $\mathrm{T}$ & $\mathrm{T}$ & Success \\
\hline 12. & $\begin{array}{l}\text { Unnamed Road,Air Bang,Curup Tengah,Kabupaten Rejang Lebong,Bengkulu } \\
\text { 39119,Indonesia }\end{array}$ & $\mathrm{T}$ & $\mathrm{T}$ & Success \\
\hline 13. & $\begin{array}{c}\text { Gg. Sukasukur } 1 \text { No.132,Kahuripan,Kec.Tawang,Tasikmalaya,Jawa Barat } \\
\text { 46115,Indonesia }\end{array}$ & $\mathrm{T}$ & $\mathrm{T}$ & Success \\
\hline 14. & $\begin{array}{c}\text { JL.Ringan-Ringan Pakandangan,Enam Lingkung,Kabupaten Padang } \\
\text { Pariaman,Sumatera Barat 25584,Indonesia }\end{array}$ & $\mathrm{T}$ & $\mathrm{T}$ & Success \\
\hline 15. & $\begin{array}{c}\text { JL.Raya Haruyan, Kabupaten Hulu Sungai Tenga, Kalimantan Selatan 71363, } \\
\text { Indonesia }\end{array}$ & $\mathrm{T}$ & $\mathrm{T}$ & Success \\
\hline 16. & $\begin{array}{l}\text { JL. Raya Cikukulu No.213, Talaga ,Caringin,Sukabumi Regency,Jawa Barat } \\
\text { 43154,Indonesia }\end{array}$ & $\mathrm{T}$ & $\mathrm{T}$ & Success \\
\hline
\end{tabular}




\begin{tabular}{|c|c|c|c|c|}
\hline 17. & $\begin{array}{c}\text { JL.Sultan Agung Gg.II No.21A.Gending } \\
\text { Sari,Gendingan,Kec.Kedungwaru,Kabupaten Tulungagung,Jawa Timur } \\
\text { 66229,Indonesia }\end{array}$ & $\mathrm{T}$ & $\mathrm{T}$ & Success \\
\hline 18. & Lampung, Indonesia. Error & $\mathrm{F}$ & $\mathrm{T}$ & Failed \\
\hline 19. & $\begin{array}{c}\text { Pegantungan,Badau,Kabupaten Belitung,Kepulauan Bangka } \\
\text { Belitung,Indonesia }\end{array}$ & $\mathrm{T}$ & $\mathrm{T}$ & Success \\
\hline 20. & $\begin{array}{c}\text { JL.Bona No.61,Singapadu,Kec.Sukawati,Kabupaten Gianyar,Bali } \\
\text { 80582,Indonesia }\end{array}$ & $\mathrm{T}$ & $\mathrm{T}$ & Success \\
\hline 21. & $\begin{array}{l}\text { Kost bpk aming rt } 05 \text { rw } 02 \text { kp mekarsari,Gg.Bata 2,Cibening ,Kec.Bungursari } \\
\text { „Kabupaten Purwakarta ,Jawa barat 41181,Indonesia }\end{array}$ & $\mathrm{T}$ & $\mathrm{T}$ & Success \\
\hline 22. & $\begin{array}{l}\text { JL.Raya Sempur,Cibogohilir,Kec.Plered,Kabupaten Purwakarta,Jawa barat } \\
\text { 41162,Indonesia }\end{array}$ & $\mathrm{T}$ & $\mathrm{T}$ & Success \\
\hline 23. & $\begin{array}{c}\text { JL.Raya Bojongsari No.13,Rt.1/Rw.7,Bojongsari Baru,Kec.Bojongsari,Kota } \\
\text { Depok,Jawa Barat 16516,Indonesia }\end{array}$ & $\mathrm{T}$ & $\mathrm{T}$ & Success \\
\hline 24. & $\begin{array}{c}\text { Gg.Taruna No.52,RT.2/RW.12,Cibubur,Kec.Ciracas,Kota Jakarta } \\
\text { Timur,Daerah Khusus Ibukota Jakarta 13720,Indonesia }\end{array}$ & $\mathrm{T}$ & $\mathrm{T}$ & Success \\
\hline 25. & Larsel., Kota Denpasar, Bali, Indonesia Error & $\mathrm{F}$ & $\mathrm{T}$ & Failed \\
\hline 26. & $\begin{array}{c}\text { JL. Kebaon No.28,Dusun III Semingkir,Kutasari,Kec.Baturaden,Kabupaten } \\
\text { Banyumas,Jawa Tengah 53151,Indonesia }\end{array}$ & $\mathrm{T}$ & $\mathrm{T}$ & Success \\
\hline 27. & $\begin{array}{c}\text { JL.JEND.Sudirman No.29,Baluti,Kandangan,Kabupaten Hulu Sungai } \\
\text { Selatan,Kalimantan Selatan 71213,Indonesia }\end{array}$ & $\mathrm{T}$ & $\mathrm{T}$ & Success \\
\hline 28. & Deli Serdang, Sumatra Utara 20585, Indonesia. Error & $\mathrm{F}$ & $\mathrm{T}$ & Failed \\
\hline 29. & $\begin{array}{l}\text { Jln. Masjid no. } 2 \text { Kramat, Kec. Kembaran Kab.Banyumas, Jawa Tengah } \\
\text { 53182, Indonesia }\end{array}$ & $\mathrm{T}$ & $\mathrm{T}$ & Success \\
\hline 30. & $\begin{array}{l}\text { 01/05 Jln. Masjid no. } 2 \text { Kramat, Kec. Kembaran Kab.Banyumas, Jawa Tengah } \\
\text { 53182, Indonesia }\end{array}$ & $\mathrm{T}$ & $\mathrm{T}$ & Success \\
\hline
\end{tabular}

\section{Pengujian field "Nomor HP"}

Aturan entri data A.5 : harus terdiri dari Nomor atau bilangan dan tidak boleh ada huruf atau karakter selain nomor.

Tabel 6. Hasil uji aturan A.5

\begin{tabular}{|c|c|c|c|c|}
\hline No & Sample Data & Expected Result & Result & Conclusion \\
\hline $\begin{array}{l}1 . \\
2 . \\
3 . \\
4 . \\
5 . \\
6 . \\
7 . \\
8 . \\
9 . \\
10 . \\
11 . \\
12 . \\
13 . \\
14 . \\
15 . \\
16 . \\
17 . \\
18 . \\
19 . \\
20 . \\
21 . \\
22 . \\
23 . \\
24 . \\
25 . \\
26 . \\
27 . \\
28 . \\
29 . \\
30 .\end{array}$ & $\begin{array}{c}089996474320 \\
082151025314 \\
08995283715 \\
08533374996 \\
083164731271 \\
083103535323 \\
081259096310 \\
089686023879 \\
08195111120 \\
081383963569 \\
087785019471 \\
083165519455 \\
085320520966 \\
081378149451 \\
082158665459 \\
085217835139 \\
085755478509 \\
082284082886 \\
083170151909 \\
85792624504 \\
0895353068481 \\
081291046298 \\
081281801050 \\
085880265252 \\
0897635412 \\
085600010858 \\
083141392777 \\
08212699623 \\
085869932173 \\
085842933326\end{array}$ & $\begin{array}{l}\mathrm{T} \\
\mathrm{T} \\
\mathrm{T} \\
\mathrm{T} \\
\mathrm{T} \\
\mathrm{T} \\
\mathrm{T} \\
\mathrm{T} \\
\mathrm{T} \\
\mathrm{T} \\
\mathrm{T} \\
\mathrm{T} \\
\mathrm{T} \\
\mathrm{T} \\
\mathrm{T} \\
\mathrm{T} \\
\mathrm{T} \\
\mathrm{T} \\
\mathrm{T} \\
\mathrm{T} \\
\mathrm{T} \\
\mathrm{T} \\
\mathrm{T} \\
\mathrm{T} \\
\mathrm{T} \\
\mathrm{T} \\
\mathrm{T} \\
\mathrm{T} \\
\mathrm{T} \\
\mathrm{T}\end{array}$ & $\begin{array}{l}\mathrm{T} \\
\mathrm{T} \\
\mathrm{T} \\
\mathrm{T} \\
\mathrm{T} \\
\mathrm{T} \\
\mathrm{T} \\
\mathrm{T} \\
\mathrm{T} \\
\mathrm{T} \\
\mathrm{T} \\
\mathrm{T} \\
\mathrm{T} \\
\mathrm{T} \\
\mathrm{T} \\
\mathrm{T} \\
\mathrm{T} \\
\mathrm{T} \\
\mathrm{T} \\
\mathrm{T} \\
\mathrm{T} \\
\mathrm{T} \\
\mathrm{T} \\
\mathrm{T} \\
\mathrm{T} \\
\mathrm{T} \\
\mathrm{T} \\
\mathrm{T} \\
\mathrm{T} \\
\mathrm{T}\end{array}$ & $\begin{array}{l}\text { Success } \\
\text { Success } \\
\text { Success } \\
\text { Success } \\
\text { Success } \\
\text { Success } \\
\text { Success } \\
\text { Success } \\
\text { Success } \\
\text { Success } \\
\text { Success } \\
\text { Success } \\
\text { Success } \\
\text { Success } \\
\text { Success } \\
\text { Success } \\
\text { Success } \\
\text { Success } \\
\text { Success } \\
\text { Success } \\
\text { Success } \\
\text { Success } \\
\text { Success } \\
\text { Success } \\
\text { Success } \\
\text { Success } \\
\text { Success } \\
\text { Success } \\
\text { Success } \\
\text { Success }\end{array}$ \\
\hline
\end{tabular}

\section{Pembahasan}

Pada hasil akhir pengujian menggunakan black box testing dengan metode boundary value analysis dapat memberikan informasi tentang serangkaian scenario yang diujikan untuk memperoleh presentasi 
keberhasilan, sehingga ditemukan hasil pengujian dari 30 skenario dengan form diatas ditemukkan error sebanyak 5 kali gagal simpan ke database dan 25 kali berhasil masuk ke database, ke empat error tersebut terjadi karena kesalahan pada saat tombol tambah koordinat di klik dan dalam pencariannya menggunakan gps dari google memakan waktu yang sangat lama bahkan sampai tidak ditemukan keberadaan koordinat dari ponsel yang digunakan. Dari rangkaian scenario diatas dapat ditemukan error terjadi karena perbedaan versi android untuk menggunakan fitur tambah koordinat secara otomatis pada aplikasi penyimpanan. Karena skenario testing dilakukan terhadap 30 orang dan 30 device dari handphone yang berbeda. Jadi prosentasi keberhasilah yang diperoleh setelah dilakukan pengujian adalah $83,33 \%$ dan juga $16,66 \%$ untuk prosentase kegagalannya.

\section{Kesimpulan}

Kesimpulan dari hasil penelitian Black box pada aplikasi penyimpanan menggunakan metode Boundary Value Analysis. Teknik Blackbox Testing Boundary Value Analysis adalah Teknik yang sangat relevan untuk diterapkan pada aplikasi Penyimpanan dengan menentukan batas minimum dan batas maksimum dari struktur data yang telah dirancang. Pengujian fungsionalitas melalui serangkaian skenario input yang diujikan menghasilkan data yang valid untuk kemudian disimpan kedalam database. Prosentase keberhasilan aplikasi setelah dilakukan pengujian adalah 5:1 dengan rate keberhasilan mencapai 83,33\%.

\section{Daftar Pustaka}

[1] I. Ismail and J. Efendi, "Black-Box Testing: Analisis Kualitas Aplikasi Source Code Bank Programming," J. JTIK (Jurnal Teknol. Inf. dan Komunikasi), vol. 4, no. 2, p. 1, 2020, doi: 10.35870/jtik.v5i1.148.

[2] W. N. Cholifah, Y. Yulianingsih, and S. M. Sagita, "Pengujian Black Box Testing pada Aplikasi Action \& Strategy Berbasis Android dengan Teknologi Phonegap," STRING (Satuan Tulisan Ris. dan Inov. Teknol., vol. 3, no. 2, p. 206, 2018, doi: 10.30998/string.v3i2.3048.

[3] J. Desember, M. Z. Faried, A. Mulwinda, and Y. Primadiyono, "Pengembangan Aplikasi Android Bimbingan Skripsi dengan Fitur Notifikasi,” J. Tek. Elektro, vol. 9, no. 2, pp. 74-79, 2017, doi: 10.15294/jte.v9i2.10657.

[4] D. Andriansyah, "Pengujian Kotak Hitam Boundary Value Analysis Pada Sistem Informasi Manajemen Konseling Tugas Akhir," vol. 7, no. 1, pp. 20-25, 2018, [Online]. Available: http://ijns.org/journal/index.php/ijns/article/view/1496.

[5] T. S. Jaya, "Pengujian Aplikasi dengan Metode Blackbox Testing Boundary Value Analysis (Studi Kasus: Kantor Digital Politeknik Negeri Lampung),” J. Inform. Pengemb. IT, vol. 3, no. 2, pp. 4546, 2018, [Online]. Available: http://www.ejournal.poltektegal.ac.id/index.php/informatika/article/view/647/640.

[6] V. Febrian, M. R. Ramadhan, M. Faisal, and A. Saifudin, "Pengujian pada Aplikasi Penggajian Pegawai dengan menggunakan Metode Blackbox,” J. Inform. Univ. Pamulang, vol. 5, no. 1, p. 61, 2020, doi: 10.32493/informatika.v5i1.4340.

[7] M. Nurudin, W. Jayanti, R. D. Saputro, M. P. Saputra, and Y. Yulianti, "Pengujian Black Box pada Aplikasi Penjualan Berbasis Web Menggunakan Teknik Boundary Value Analysis," J. Inform. Univ. Pamulang, vol. 4, no. 4, p. 143, 2019, doi: 10.32493/informatika.v4i4.3841.

[8] AHMAD FARKI, "PENGARUH ONLINE CUSTOMER REVIEW DAN RATING TERHADAP KEPERCAYAAN DAN MINAT PEMBELIAN PADA ONLINE MARKETPLACE DI INDONESIA,” p. 215, 2016.

[9] D. Debiyanti, S. Sutrisna, B. Budrio, A. K. Kamal, and Y. Yulianti, "Pengujian Black Box pada Perangkat Lunak Sistem Penilaian Mahasiswa Menggunakan Teknik Boundary Value Analysis," J. Inform. Univ. Pamulang, vol. 5, no. 2, p. 162, 2020, doi: 10.32493/informatika.v5i2.5446.

[10] M. Sholeh, I. Gisfas, Cahiman, and M. A. Fauzi, "Black Box Testing on ukmbantul.com Page with Boundary Value Analysis and Equivalence Partitioning Methods," vol. 1823, no. 1, p. 12029, Mar. 2021, doi: 10.1088/1742-6596/1823/1/012029. 